\title{
PET Imaging Reveals Early Pulmonary Perfusion Abnormalities in HIV Infection Similar to Smoking
}

\author{
Puja Kohli ${ }^{1,2}$, Vanessa J. Kelly ${ }^{1}$, Kathryn A. Hibbert ${ }^{1,2}$, Björn Corleis ${ }^{3}$, Mamary Kone ${ }^{1}$, Josalyn L. Cho ${ }^{4}$, \\ Doreen DeFaria-Yeh ${ }^{2,5}$, Douglas S. Kwon ${ }^{2,3,6}$, Benjamin D. Medoff ${ }^{1,2}$, R. Scott Harris ${ }^{1}$, and Tilo Winkler ${ }^{7}$ \\ ${ }^{1}$ Division of Pulmonary and Critical Care at Massachusetts General Hospital, Boston, Massachusetts; ${ }^{2}$ Department of Medicine, \\ Harvard Medical School, Boston, Massachusetts; ${ }^{3}$ The Ragon Institute of MGH, MIT and Harvard, Cambridge, Massachusetts; \\ ${ }^{4}$ Department of Internal Medicine, University of Iowa Carver College of Medicine, Iowa City, Iowa; ${ }^{5}$ Division of Cardiology, \\ Massachusetts General Hospital, Boston, Massachusetts; ${ }^{6}$ Division of Infectious Disease, Massachusetts General Hospital, Boston, \\ Massachusetts; and ${ }^{7}$ Department of Anesthesia, Critical Care and Pain Medicine, Massachusetts General Hospital, Boston, \\ Massachusetts
}

\begin{abstract}
Chronic obstructive pulmonary disease (COPD) is the most common noninfectious pulmonary disease among people living with HIV, independent of smoking. However, the cause for this enhanced susceptibility remains unclear, and the effects of HIV on pulmonary perfusion and ventilation are unknown. Methods: We used PET/CT in 46 smokers and nonsmokers, 23 of whom had documented HIV infection. Emphysema was assessed by CT and perfusion by ${ }^{13} \mathrm{~N}\left({ }^{13} \mathrm{NN}\right)$ PET scans. After removal of image noise, vertical and axial gradients in perfusion were calculated. We tested for differences in the total spatial heterogeneity of perfusion $\left(\mathrm{CV}^{2}{ }_{\mathrm{Qtotal}}\right)$ and its components $\left(\mathrm{CV}^{2}{ }_{\mathrm{Qtotal}}=\right.$ $\mathrm{CV}^{2}{ }_{\text {Qvgrad }}$ [vertical gradient] $+\mathrm{CV}^{2}{ }_{\text {Qzgrad }}$ [axial gradient] $+\mathrm{CV}^{2} \mathrm{Qr}$ [residual heterogeneity]) among groups. Results: There were no significant differences in demographic parameters among groups, and all subjects had minimal radiographic evidence of emphysema. Compared with controls, nonsmokers living with HIV had a significantly greater $\mathrm{CV}^{2}{ }_{\mathrm{Qr}} / \mathrm{CV}^{2}{ }_{\mathrm{Qtotal}}(0.48$ vs. $0.36, P=0.05)$ and reduced $\mathrm{CV}^{2}{ }_{\text {Qvgrad }} / \mathrm{CV}^{2}{ }_{\text {Qtotal }}(0.46$ vs. $0.65, P=0.038)$. Smokers also had a reduced $\mathrm{CV}^{2}{ }_{\text {Qvgrad }} / \mathrm{CV}^{2}{ }_{\text {Qtotal }}$, however, there was no significant difference in $\mathrm{CV}^{2}{ }_{\mathrm{Qvgrad}} / \mathrm{CV}^{2}{ }_{\text {Qtotal }}$ between smokers living with and without HIV (0.39 vs. $0.34, P=0.58$ ), despite a decreased vertical perfusion gradient $\left(\mathrm{Qv}_{\mathrm{grad}}\right)$ in smokers living with HIV. Conclusion: In nonsmokers living with well-controlled HIV and minimal radiographic emphysema, HIV infection contributes to pulmonary perfusion abnormalities similar to smokers. These data indicate the onset of subclinical pulmonary perfusion abnormalities that could herald the development of significant lung disease in these susceptible individuals.
\end{abstract}

Key Words: vascular; HIV; PET/CT; pulmonary perfusion; pulmonary vascular disease

J Nucl Med 2021; 62:405-411

DOI: 10.2967/jnumed.120.245977

C hronic obstructive pulmonary disease (COPD) is a major cause of morbidity and mortality in individuals living with $\operatorname{HIV}(1,2)$. Approximately $20 \%$ of individuals living with HIV are estimated to have airflow obstruction $(3,4)$, and although there is a higher prevalence of smoking

Received Mar. 29, 2020; revision accepted Jun. 30, 2020

For correspondence or reprints contact: Puja Kohli, Massachusetts General Hospital, 55 Fruit St., BUL 148, Boston, MA 02114.

E-mail: pkohli1@mgh.harvard.edu

Published online Aug. 6, 2020.

COPYRIGHT (C 2021 by the Society of Nuclear Medicine and Molecular Imaging. in patients living with HIV (5), the increased incidence of COPD is out of proportion to what would be expected. Interestingly, nearly 1 in 6 nonsmokers living with HIV also have emphysematous changes in their lungs (2), implicating unrecognized mechanisms promoting COPD among those living with HIV. Despite the improved outcomes with antiretroviral therapy (HAART [highly active antiretroviral therapy]), individuals living with HIV continue to have accelerated development of COPD, leading to increased morbidity and mortality (6).

The mechanisms that promote accelerated COPD in HIV infection are incompletely understood. In COPD, regional and systemic inflammation in response to inhaled toxins is thought to cause airway injury and tissue destruction. Dysfunction of the pulmonary vasculature in response to such inflammation has been implicated as a critical event in the pathogenesis of $\operatorname{COPD}(7,8)$. In vitro, HIV-associated proteins have been shown to induce dysfunctional vasoconstriction, endothelial proliferation, and plexiform lesions (9). This suggests that HIV infection induces additional dysfunction of the pulmonary vasculature beyond smoking alone, which may contribute to the development of accelerated COPD compared with individuals without HIV. However, studies assessing the effect of HIV on regional pulmonary blood flow and tissue destruction are lacking. Gaining greater insight into the role of pulmonary perfusion in the pathogenesis of COPD in this population is vital to identifying effective and specific therapeutic targets.

In this study, we investigated pulmonary perfusion and ventilation using ${ }^{13} \mathrm{NN}$-saline PET/CT imaging for quantitative characterization of the spatial distributions of pulmonary perfusion (perfusion heterogeneity) and ventilation $(8,10-13)$ and components of the perfusion heterogeneity, including gradients in the dorsoventral and craniocaudal direction. These gradients are primarily caused by hydrostatic pressure and regional systematic differences in structure or function of the vascular tree. After removing these gradients, the residual heterogeneity in perfusion provides insight into the remaining anatomic and vasoactive variations in pathway resistance. We aimed to test our hypothesis that chronic HIV infection promotes pulmonary vascular dysfunction, manifesting as increased pulmonary perfusion heterogeneity before tissue destruction in the lung parenchyma.

\section{MATERIALS AND METHODS}

\section{Subjects}

The study was approved by the Institutional Review Board (IRB) of the Massachusetts General Hospital, protocol no. 2013P002436. 
TABLE 1

Baseline Clinical Characteristics

\begin{tabular}{|c|c|c|c|c|c|}
\hline \multirow[b]{2}{*}{ Trait } & \multicolumn{2}{|c|}{ Nonsmoker } & \multicolumn{2}{|c|}{ Smoker } & \multirow[b]{2}{*}{$\mathrm{p}_{\mathrm{kw}}$ value } \\
\hline & HIV- & $\mathrm{HIV}+$ & HIV- & $\mathrm{HIV}+$ & \\
\hline$n$ & 15 & 11 & 7 & 12 & \\
\hline Age, mean (SD) & $37(16)$ & $52(9)$ & $51(7)$ & $51(8)$ & 0.002 \\
\hline Race, white & $10(66.7 \%)$ & $8(72.7 \%)$ & $5(71.4 \%)$ & $4(33.3 \%)$ & 0.10 \\
\hline Sex, female & $8(53.3 \%)$ & $1(9.1 \%)$ & $1(14.3 \%)$ & $2(16.7 \%)$ & 0.04 \\
\hline Body mass index (SD) & $25.8(3.7)$ & $26.7(2.6)$ & $24.5(3.2)$ & $26.9(2.8)$ & 0.37 \\
\hline Pack Years (SD) & 0 & 0 & $16.3(11.4)$ & $12.8(7.2)$ & \\
\hline Prior smokers, $<5$ pack y & 5 (33.3\%) & $5(45.5 \%)$ & 0 & 0 & \\
\hline Current HAART & 0 & $9(81.8 \%)$ & 0 & $11(91.7 \%)$ & \\
\hline Viral load & 0 & $<40$ & 0 & $<90$ & \\
\hline
\end{tabular}

Continuous variables are represented as mean (SD), and categoric variables are represented as counts (proportions). $p_{\mathrm{kw}}=P$ value of the Kruskal-Wallis test.

Verbal and signature of written informed consent were obtained from each subject before the study. Inclusion criteria were adult volunteers of either sex, ages 18-65 y. Subjects living with HIV were required to have a viral load drawn at the time of enrollment. Subjects enrolled without HIV were required to have a documented HIV-negative antibody screening test within the previous 6 mo. All subjects were required to have laboratory values within $45 \mathrm{~d}$ of enrollment that met the following criteria: hemoglobin $\geq 10 \mathrm{~g} / \mathrm{dL}$, absolute neutrophil count $\geq 1,000 / \mathrm{mm}^{3}$, platelet count $\geq 80,000 / \mathrm{mm}^{3}$, prothrombin time (PT) $<1.5 \times$ upper limit of normal, partial thromboplastin time $1.5 \times$ upper limit of normal, and, for female participants, a negative urine pregnancy test (sensitive to $25 \mathrm{IU}$ human chorionic gonadotropin) at screening and within $24 \mathrm{~h}$ of the study procedures.

All subjects underwent screening spirometry. Patients were eligible for participation in the study if pulmonary function was within normal limits (forced expiratory volume in first second [FEV1]/forced vital capacity $[\mathrm{FVC}]>0.7)$ or revealed GOLD I $(\mathrm{FEV} 1 / \mathrm{FVC}<0.7$ and
FEV $1 \geq 80 \%$ predicted) or GOLD II (FEV1/FVC $<0.7$ and $\geq 50 \%$ and $<80 \%$ predicted) obstructive airways disease.

Exclusion criteria included any female subjects who were pregnant or less than 3 mo postpartum as well as any history of coronary artery disease; myocardial infarction; chronic renal insufficiency; decompensated cirrhosis; and intolerance or allergy to ester type anesthetics, benzodiazepines, or opiates. Medication use exclusions included any subjects taking anticoagulants or antiplatelet agents that could not be stopped for at least 1 wk; systemic steroids, interleukins, systemic interferons, systemic chemotherapy, immunomodulatory agents, or antibiotic therapy within $30 \mathrm{~d}$ before study enrollment; and any prior receipt of the HIV vaccine.

Subjects living with HIV receiving HAART as part of their treatment were maintained on those therapies on the day of study.

\section{Functional Imaging of Pulmonary Perfusion and Ventilation}

Subjects were positioned supine and with arms abducted on the table of the PET/CT scanner (Biograph 64; Siemens Healthcare). Relative

TABLE 2

Baseline Physiologic Characteristics

\begin{tabular}{|c|c|c|c|c|c|}
\hline \multirow[b]{2}{*}{ Trait } & \multicolumn{2}{|c|}{ Nonsmoker } & \multicolumn{2}{|c|}{ Smoker } & \multirow[b]{2}{*}{$\mathrm{p}_{\mathrm{kw}}$ value } \\
\hline & HIV- & HIV+ & HIV- & $\mathrm{HIV}+$ & \\
\hline$\% H U 950 \mathrm{MLV}^{*}$ & $1.51(2.5)$ & $1.53(1.94)$ & $1.5(1.17)$ & $1.31(1.82)$ & 0.99 \\
\hline$\% H U 910_{M L V^{*}}$ & $5.89(11.36)$ & $3.55(2.44)$ & $5.94(4.45)$ & $2.46(2.02)$ & 0.56 \\
\hline PASP (range) & 31.71 (25-39) & $35.25(30-40)$ & $31.45(23-44)$ & $33.81(32-37)$ & 0.76 \\
\hline FEV $_{1}$ & $3.62(0.72)$ & $3.61(0.53)$ & $3.37(0.68)$ & $3.34(0.81)$ & 0.66 \\
\hline $\mathrm{FEV}_{1}, \%$ predicted & $100.45(16.05)$ & $94.83(16.8)$ & 105.92 (25.96) & $107.11(13.73)$ & 0.36 \\
\hline FVC & $4.52(0.85)$ & $4.43(0.70)$ & $4.24(0.85)$ & $4.1(0.99)$ & 0.62 \\
\hline FVC, \% predicted & $102.38(14.52)$ & 98.31 (14.70) & $108(24.61)$ & 113.39 (13.32) & 0.14 \\
\hline
\end{tabular}

*Measurement of Hounsfield units at MLV likely underestimates the amount of emphysema typically measured at total lung capacity (TLC).

Continuous variables are represented as mean (SD).

$\mathrm{p}_{\mathrm{kw}}=P$ value of the Kruskal-Wallis test; $\% \mathrm{HU} 50_{\mathrm{MLV}}=$ percentage of voxels with measured Hounsfield units $<-950$ at MLV; $\% \mathrm{HU}_{10} \mathrm{MLV}_{\mathrm{ML}}=$ percentage of voxels with measured Hounsfield units $<-910$ at MLV; PASP $=$ pulmonary arterial systolic pressure; FEV $1=$ forced expiratory volume in first second; FVC = forced vital capacity. 


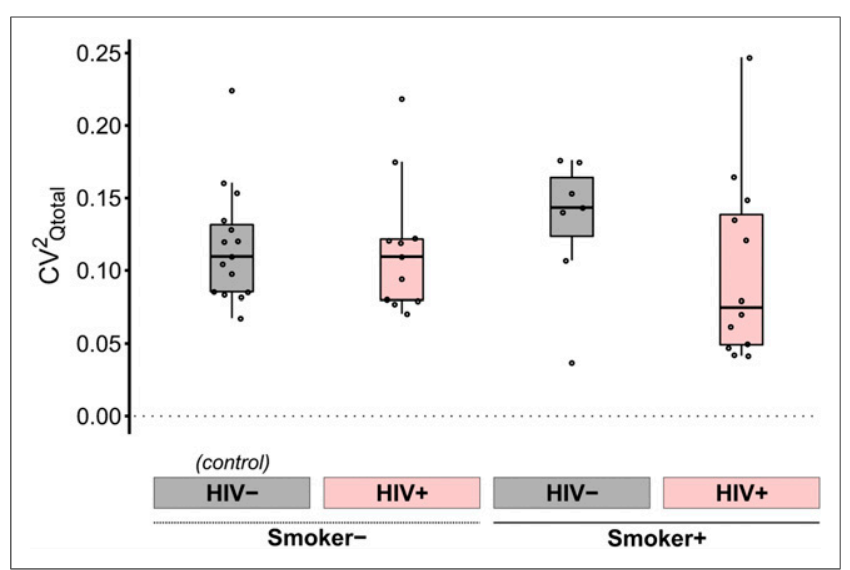

FIGURE 1. Total perfusion heterogeneity excluding imaging noise $\left(\mathrm{CV}^{2}{ }_{\text {Qtotal }}\right)$ was not different among controls, nonsmokers living with HIV, smokers without HIV infection, and smokers living with HIV. Boxplots include median and 25th and 75th percentiles of each group.

lung volume was continuously measured using impedance plethysmography (SomnoStar PT; SensorMedics Corp.). After calibration of the plethysmograph, mean lung volume (MLV) was determined during $30 \mathrm{~s}$ of steady tidal breathing before imaging. We then acquired a topogram CT scan to determine the field of view for PET and for CT scans. In preparation for a CT scan, subjects were asked to inhale to total lung capacity, followed by slow exhalation to MLV, and to hold their breath for $<10 \mathrm{~s}$ while the CT scan was acquired. After this, a dynamic ${ }^{13} \mathrm{NN}$ PET scan was acquired (14) starting with a 30-s breath hold at MLV. Radiation doses for all subjects ranged from $3.1-3.5 \mathrm{mSv}$.

Perfusion and ventilation images were generated from the ${ }^{13} \mathrm{NN}-$ saline PET scan, using a tracer kinetics analysis that has been described previously $(14,15)$. Briefly, nitrogen has a very low solubility in blood so that ${ }^{13} \mathrm{NN}$ diffuses during its passage through the pulmonary capillaries rapidly out of the blood into the alveolar gas space, where it accumulates during the breath hold, reaching a plateau that is directly proportional to the relative perfusion. Thus, ${ }^{13} \mathrm{NN}$ PET images of the plateau activity normalized by the mean of the entire lung are images of relative perfusion. After the breath hold, the subject resumes tidal breathing, which results in a washout of the ${ }^{13} \mathrm{NN}$ by ventilation with a washout rate proportional to the specific ventilation $(\mathrm{sV})$ of the voxel: $\mathrm{sV}=$ alveolar ventilation $\left(\mathrm{V}_{\mathrm{A}}\right)$ /alveolar volume.

The degree of lung inflation was quantified as the fraction of gas content $\left(\mathrm{F}_{\mathrm{gas}}\right)$. Specifically, Hounsfield units $(\mathrm{HU})$ of CT scans were converted to $\mathrm{F}_{\text {gas }}$ using $\mathrm{F}_{\text {gas }}=$ (tissue density - density value of the voxel)/(tissue density - density of air) where tissue density $=0 \mathrm{HU}$ and density of gas $=-1,000 \mathrm{HU}$. Tissue fraction $\left(\mathrm{F}_{\text {tis }}\right)$ images were calculated using $\mathrm{F}_{\text {tis }}=1-\mathrm{F}_{\text {gas }}$.

\section{Perfusion Heterogeneity}

Heterogeneity of different parameters were quantified as the square of the coefficient of variation $\left(\mathrm{CV}^{2}=(\mathrm{SD} / \text { mean })^{2}\right)(13)$. Relative perfusion images were used to calculate total spatial heterogeneity of perfusion $\left(\mathrm{CV}^{2}{ }_{\mathrm{Qtotal}}\right)$. The $\mathrm{CV}^{2}{ }_{\text {Qtotal }}$ was then separated into components caused by systematic gradients in the vertical (dorsoventral) direction $\left(\mathrm{CV}^{2}\right.$ Qvgrad $)$, the axial (craniocaudal) direction $\left(\mathrm{CV}^{2}{ }_{\text {Qzgrad }}\right)$, and the remaining, or residual heterogeneity $\left(\mathrm{CV}^{2}{ }_{\mathrm{Qr}}\right)$, such that $\mathrm{CV}^{2}{ }_{\mathrm{Qtotal}}=$ $\mathrm{CV}_{\text {Qvgrad }}^{2}+\mathrm{CV}_{\text {Qzgrad }}^{2}+\mathrm{CV}^{2}{ }_{\mathrm{Qr}}$

\section{Ventilation Heterogeneity}

${ }^{13} \mathrm{NN}$ washout rates were used to calculate the heterogeneity of ventilation $\left(\mathrm{CV}^{2}{ }_{\mathrm{sV}}\right)$. Since imaging noise cannot be removed from $\mathrm{CV}^{2}{ }_{\mathrm{sV}}$, we did not separate $\mathrm{CV}^{2}{ }_{\mathrm{sV}}$ into its components (13).

\section{Statistical Analysis}

Our primary outcomes of interest were total spatial heterogeneity of perfusion $\left(\mathrm{CV}^{2}{ }_{\mathrm{Qtotal}}\right)$ and its components. In secondary analyses, we assessed various regional perfusion, ventilation, and composite metrics. We first implemented the Kruskal-Wallis nonparametric test of variance to test whether there was a difference in rank order of each metric across the study groups: controls (nonsmokers without HIV infection), nonsmokers living with HIV, smokers without HIV infection, and smokers living with HIV. For comparisons attaining $P<0.05$, we performed specific comparisons between individual groups by Wilcoxon rank sum. Multiple-hypothesis testing correction was performed using the Tukey-Kramer method (SAS for Windows, version 9.4; SAS Institute Inc.). For secondary and exploratory correlation analyses, Spearman rank-order correlations were performed. Statistical significance was set at $P<0.05$. Data are presented as mean (SD) unless otherwise stated.

\section{RESULTS}

\section{Subjects}

General clinical characteristics of the subjects are presented in Table 1 and physiologic characteristics in Table 2. All subjects living with HIV had viral loads $<90$, and all but 3 (designated as elite controllers) were on HAART. All smokers reported $>10$ pack years of smoking. Controls were younger and included more female participants than the other groups. (Table 1) There were no significant differences in spirometry between groups. (Table 2)

TABLE 3

Regional Perfusion Distribution

\begin{tabular}{|c|c|c|c|c|c|}
\hline \multirow[b]{2}{*}{ Trait } & \multicolumn{2}{|c|}{ Nonsmoker } & \multicolumn{2}{|c|}{ Smoker } & \multirow[b]{2}{*}{$\mathrm{p}_{\mathrm{kw}}$ value } \\
\hline & HIV- & $\mathrm{HIV}+$ & HIV- & $\mathrm{HIV}+$ & \\
\hline$Q v_{\text {grad }}\left(10^{-2} \mathrm{~cm}^{-1}\right)$ & $6.96(1.31)^{\star \dagger \ddagger}$ & $5.32(1.83)^{\ddagger}$ & $4.88(1.79)^{\dagger}$ & $4.7(1.66)^{\star}$ & 0.003 \\
\hline $\mathrm{CV}^{2}$ Qtotal & $0.12(0.04)$ & $0.12(0.05)$ & $0.13(0.05)$ & $0.1(0.06)$ & 0.59 \\
\hline $\mathrm{CV}^{2}{ }_{\text {Qvgrad }} / \mathrm{CV}^{2}{ }_{\text {Qtotal }}$ & $0.65(0.13)^{\star \dagger \ddagger}$ & $0.46(0.19)^{\ddagger}$ & $0.34(0.17)^{\dagger}$ & $0.39(0.16)^{\star}$ & 0.002 \\
\hline $\mathrm{CV}^{2}{ }_{\text {Qzgrad }} / \mathrm{CV}^{2}{ }_{\text {Qtotal }}$ & $0.04(0.05)$ & $0.07(0.08)$ & $0.11(0.13)$ & $0.1(0.13)$ & 0.23 \\
\hline $\mathrm{CV}^{2}{ }_{\mathrm{Qr}} / \mathrm{CV}^{2}{ }_{\text {Qtotal }}$ & $0.36(0.13)$ *t‡ & $0.48(0.15)^{\ddagger}$ & $0.54(0.15)^{\dagger}$ & $0.51(0.13)$ * & 0.013 \\
\hline
\end{tabular}

Variables are represented as mean (SD).

${ }^{*}+$ Indicate $P$ value $<0.05$ in with Wilcoxon rank-sum testing.

$\mathrm{p}_{\mathrm{kw}}=P$ value of the Kruskal-Wallis test. 


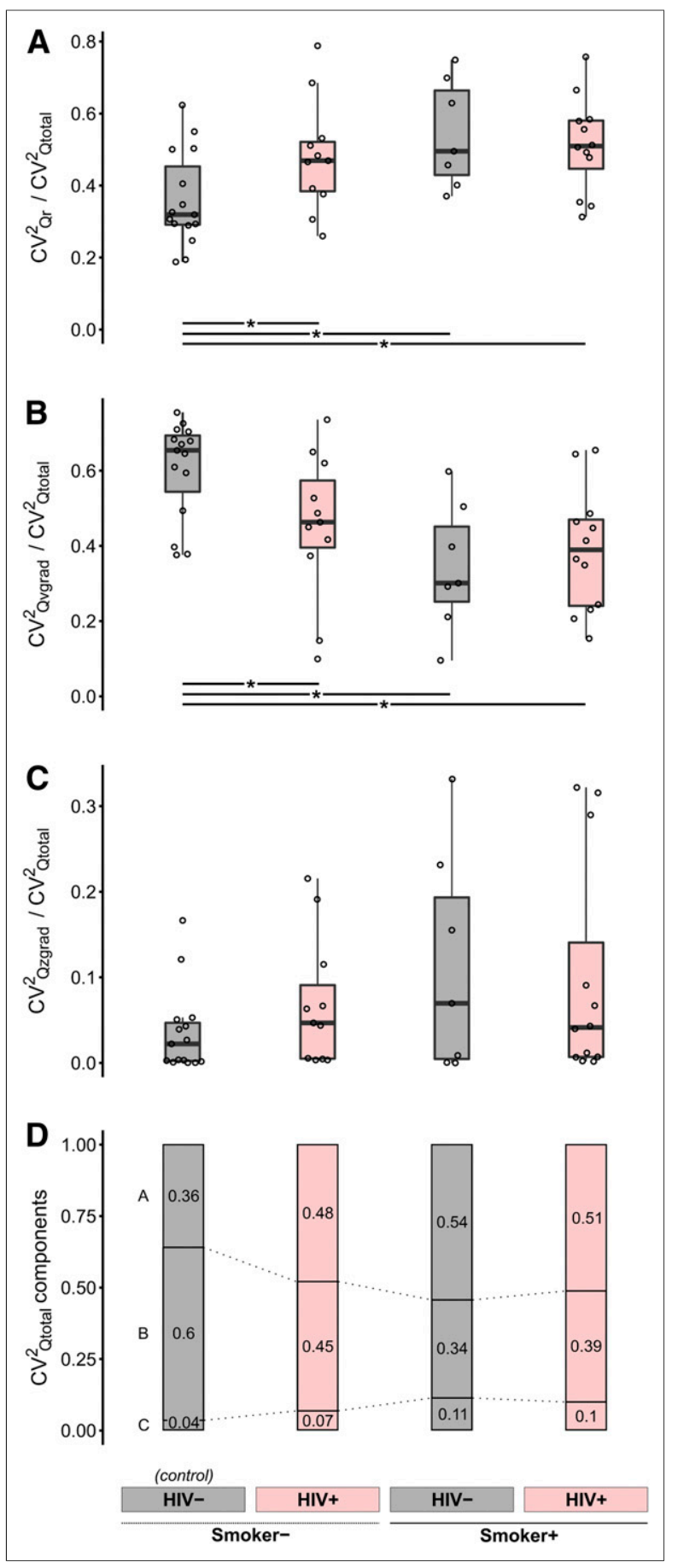

FIGURE 2. Components of perfusion heterogeneity revealed nonsmokers living with HIV have spatial perfusion abnormalities similar to smokers. Components normalized by total spatial heterogeneity of perfusion $\left(\mathrm{CV}^{2}{ }_{\text {Qtotal }}\right)$ show that smokers, regardless of HIV infection, demonstrated increased contribution of residual perfusion heterogeneity $\left(\mathrm{CV}^{2}{ }_{\mathrm{Qr}} / \mathrm{CV}^{2}{ }_{\mathrm{Qtotal}}\right)(\mathrm{A})$ with a significantly diminished contribution of vertical perfusion gradient $\left(\mathrm{CV}^{2}{ }_{\mathrm{Qvgrad}} / \mathrm{CV}^{2}{ }_{\mathrm{Qtotal}}\right)(\mathrm{B})$ as compared with controls. There was no significant difference in axial gradient $\left(\mathrm{CV}^{2}{ }_{\mathrm{Qzgrad}} /\right.$ $\mathrm{CV}^{2}$ Qtotal) among groups (C). Nonsmokers living with HIV exhibited a similar pattern, with values of high $\mathrm{CV}^{2}{ }_{\mathrm{Q}} / \mathrm{CV}^{2}{ }_{\mathrm{Qtotal}}$ and reduced $\mathrm{CV}^{2}{ }_{\text {Qvgrad }} / \mathrm{CV}^{2}{ }_{\text {Qtotal }}$ approaching that of smokers as shown by mean values of component contributions (D). (A-C) Significant differences in mean values are marked underneath the boxplots ${ }^{*} P<0.05$ ). (D) Letters $\mathrm{A}-\mathrm{C}$ correspond to components of heterogeneity in panels above.

\section{Regional Perfusion Distribution}

The total heterogeneity of perfusion $\left(\mathrm{CV}^{2}\right.$ Qtotal $)$ was not different among groups $\left(P\right.$ value of the Kruskal-Wallis test $\left.\left[p_{\mathrm{kw}}\right]=0.59\right)$. (Fig. 1) However, the components of $\mathrm{CV}^{2}$ Qtotal $\left(\mathrm{CV}^{2}{ }_{\text {Qvgrad, }} \mathrm{CV}^{2}\right.$ Qzgrad, $\mathrm{CV}^{2}{ }_{\mathrm{Qr}}$ ) distinguished the groups (Table 3; Fig. 2). Despite a younger mean age in the control group, age was not associated with any of these primary outcome measures within the control group.

Among nonsmokers, subjects living with HIV had a significantly lower contribution of the vertical perfusion gradient $\left(\mathrm{CV}^{2}{ }_{\mathrm{Qvgrad}} /\right.$ $\mathrm{CV}^{2}$ Qtotal $)$ than controls ( 0.46 vs. $\left.0.65, P=0.038\right)$, approaching values similar to those seen in smokers (Table 3; Fig. 2). Current smokers had a significantly smaller $\mathrm{CV}^{2}{ }_{\mathrm{Qvgrad}} / \mathrm{CV}^{2}$ Qtotal than nonsmokers (0.36 vs. $0.6, P=0.002)$. However, among smokers, there was no significant difference in $\mathrm{CV}^{2}{ }_{\text {Qvgrad }} / \mathrm{CV}^{2}{ }_{\text {Qtotal }}$ between those living with and without HIV infection ( 0.39 vs. $0.34, P=0.58)$.

The median slope of the vertical gradient of perfusion $\left(\mathrm{Q}_{\mathrm{vgrad}}\right)$ demonstrated a stepwise decrement from controls $(-6.96 \pm 1.31)$ to nonsmokers living with $\mathrm{HIV}\left(-5.32 \pm 1.8310^{-2} \mathrm{~cm}^{-1}\right)$ to smokers without HIV infection $\left(-4.88 \pm 1.7910^{-2} \mathrm{~cm}^{-1}\right)$ to smokers living with HIV $\left(-4.7 \pm 1.6610^{-2} \mathrm{~cm}^{-1}\right)$. All groups demonstrated significantly lower $\mathrm{Q}_{\mathrm{vgrad}}$ than controls $\left(\mathrm{p}_{\mathrm{kw}}=\right.$ 0.003). (Table 3; Fig. 3; Supplemental Fig. 1 [supplemental materials are available at http://jnm.snmjournals.org]). Notably, 11 of $13(85 \%)$ subjects with a $\mathrm{Q}_{\text {vgrad }}$ below the range of controls were subjects living with HIV (Fig. 4).

The contribution of the residual heterogeneity to total heterogeneity of perfusion $\left(\mathrm{CV}^{2}{ }_{\mathrm{Qr}} / \mathrm{CV}^{2}{ }_{\mathrm{Qtotal}}\right)$ was higher in all groups compared with the control group $\left(\mathrm{p}_{\mathrm{kw}}=0.01\right)$. Nonsmokers living with HIV demonstrated a residual perfusion heterogeneity similar

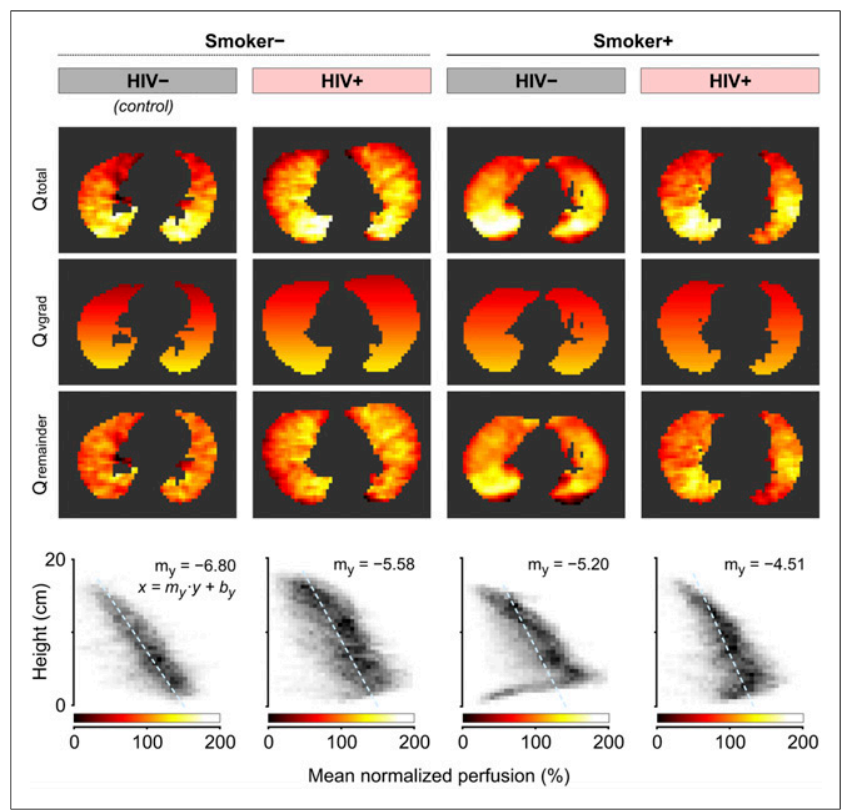

FIGURE 3. Slope of vertical gradient in perfusion was attenuated with HIV infection and smoking. Representative axial slices of PET perfusion images (upper row) and height versus mean-normalized perfusion plots (lower row) are presented for individual from each group who had median vertical gradient in perfusion $\left(Q_{v g r a d}\right)$. Vertical gradient in perfusion was significantly greater (more negative slope) in controls as compared with other groups ( $p_{\text {anova }}=0.003$ ), and there was a stepwise decrement from controls to nonsmokers living with HIV to smokers without HIV infection to smokers living with HIV. 


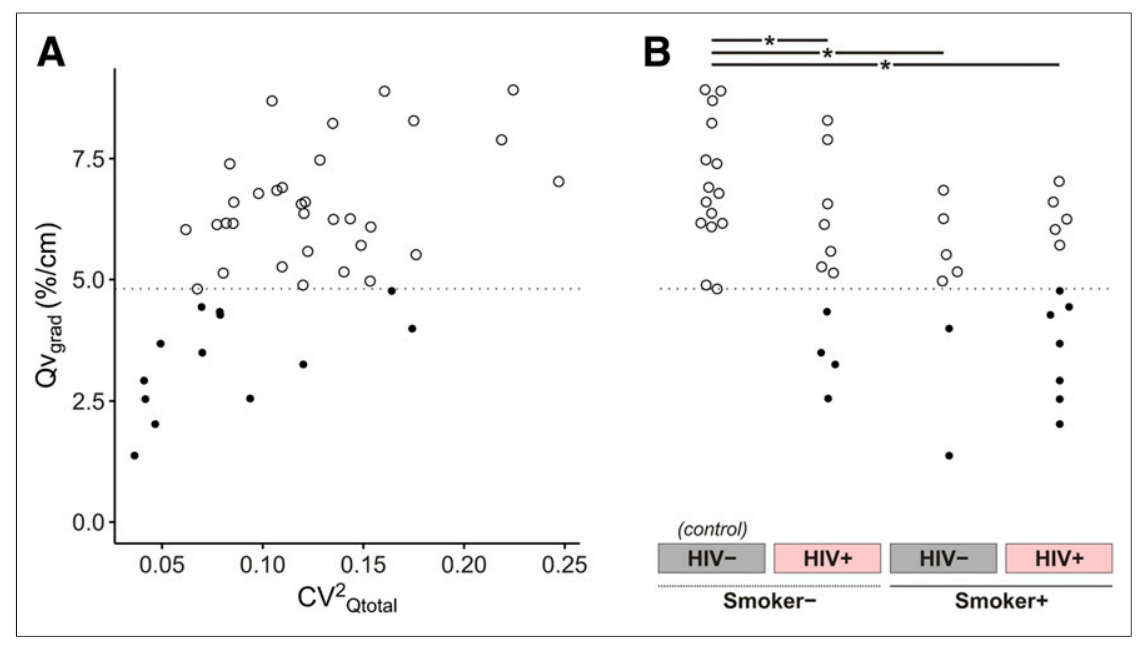

FIGURE 4. Subjects with vertical perfusion gradients below range of controls were those living with HIV. Slope of vertical gradient of perfusion $\left(Q_{v g r a d}\right)$ correlated with $\mathrm{CV}^{2}{ }_{\text {Qtotal }}(r=0.53, P=0.0002)$ (A), given a more negative $Q_{v g r a d}$ (greater slope) contributes to greater perfusion heterogeneity. $Q_{v g r a d}$ also demonstrated a stepwise decrement from controls to smokers living with HIV (B), with significant differences from controls ( ${ }^{*} P<0.05$ ). Notably, most subjects with a $Q_{v g r a d}$ below range of controls $(\bullet)$ were subjects living with HIV, except 2 noninfected smokers. Dotted line marks lowest vertical perfusion gradient of controls. Each data point in A corresponds to data point with same $Q_{v g r a d}$ in $B$.

to smokers $(P=0.41)$. Smokers had similar $\mathrm{CV}^{2} \mathrm{Qr}$ regardless of HIV status $(P=0.65)$ (Table 3; Fig. 2).

\section{Regional Ventilation Distribution}

Lung parenchymal density (estimated by $\mathrm{F}_{\text {tis }}$ ) was similar across all groups. However, the slope of the vertical gradient of specific ventilation $\left(\mathrm{sV}_{\text {grad }}\right)$ was nonsignificantly lower in all groups compared with controls $\left(\mathrm{p}_{\mathrm{kw}}=0.09\right)$. There was a stepwise decline in $\mathrm{sV}_{\text {grad }}$ when comparing nonsmokers living with HIV with smokers without HIV with to smokers living with HIV, with smokers living with HIV having the lowest $\mathrm{sV}_{\text {grad }}$ compared with their counterparts (Supplemental Table 1).

Compared with controls, the heterogeneity of specific ventilation $\left(\mathrm{CV}^{2}{ }_{\mathrm{sV}}\right)$ was greater in nonsmokers living with HIV and smokers

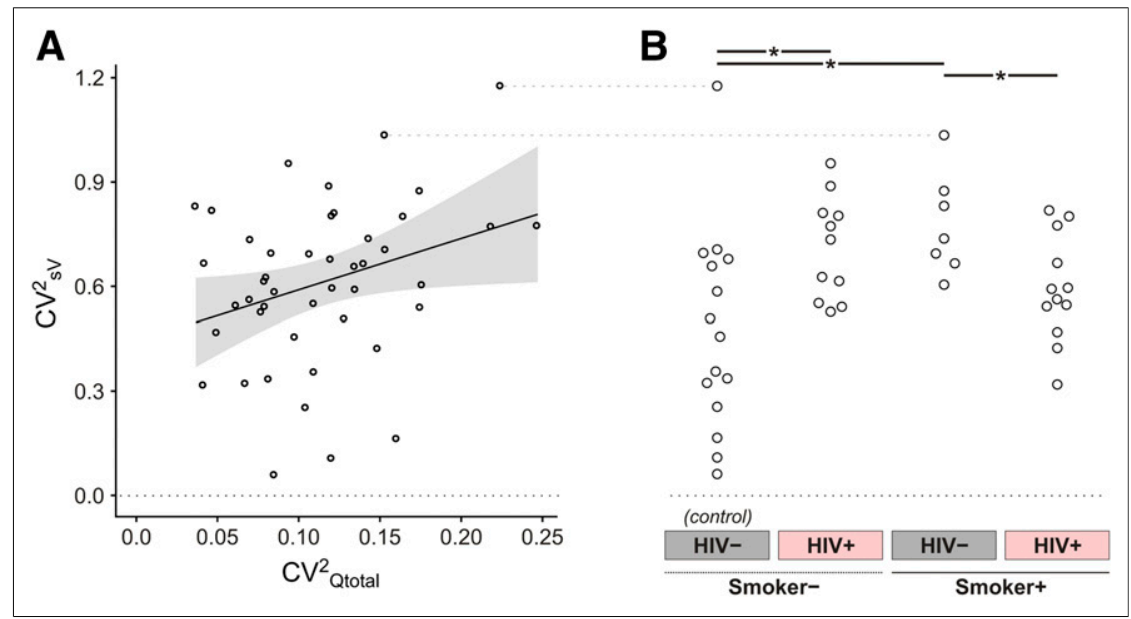

FIGURE 5. Heterogeneity of specific ventilation $\left(\mathrm{CV}^{2}{ }_{\mathrm{sV}}\right)$ was not closely correlated with perfusion heterogeneity $\left(\mathrm{CV}^{2}{ }_{\text {Qtotal }}\right)(r=0.26, P=0.08)(\mathrm{A})$. However, there were some significant differences among groups $\left({ }^{\star} P<0.05\right)(B)$, following a pattern similar to, although not strongly correlated with, residual heterogeneity in perfusion $\left(\mathrm{CV}^{2}{ }_{\mathrm{sv}}\right.$ vs $\left.\mathrm{CV}^{2}{ }_{\mathrm{Q}}, r=0.43, P=0.003\right)$. Each data point in $\mathrm{A}$ corresponds to data point with same $\mathrm{CV}^{2} \mathrm{sV}$ in $\mathrm{B}$. without HIV infection, following a pattern similar to, although not strongly correlated with, the residual heterogeneity in perfusion $\left(\mathrm{CV}_{\mathrm{sV}}^{2}\right.$ vs. $\left.\mathrm{CV}_{\mathrm{Qr}}{ }_{\mathrm{Qr}} r=0.43, P=0.003\right) . \mathrm{CV}^{2}{ }_{\mathrm{sV}}$ was also not strongly correlated with the total heterogeneity of perfusion $\left(\mathrm{CV}^{2}\right.$ Qtotal $)$ ( $r=0.26, P=0.08$ ) (Fig. 5; Supplemental Table 1).

\section{Ventilation-Perfusion Distribution}

The distributions of ventilation-perfusion ratios did not distinguish subjects based on HIV infection or smoking status. The distributions were unimodal in all subjects, except 2 control subjects and 1 smoker living with HIV who had bimodal distributions (Supplemental Table 2; Supplemental Fig. 2).

\section{DISCUSSION}

We performed functional ${ }^{13} \mathrm{NN}$ PET imaging on 46 subjects to characterize early subclinical pulmonary perfusion abnormalities in the setting of HIV infection and smoking. This study had 2 major findings: first, among nonsmokers, subjects living with HIV infection had an increased residual perfusion heterogeneity with a diminished dorsoventral perfusion gradient, approaching values similar to smokers; and second, among smokers, living with HIV infection led to a further reduction in the mean slope of the vertical gradient of perfusion. These results permit several conclusions. Controlled HIV infection alone or associated factors such as HAART promote subclinical abnormalities in pulmonary perfusion analogous to smoking that are identified by pulmonary perfusion imaging. Among smokers, controlled HIV infection further contributes to the development of early perfusion abnormalities. These perfusion findings in smokers and patients living with HIV may precede the development of overt lung disease, providing novel screening metrics for early disease and targets for potential therapeutic modulation to prevent possible progression of disease.

Lung diseases among persons living with HIV are more common than in the general population and remain leading causes of morbidity and mortality despite successful HAART. The central role of dysfunctional immune activation and augmented inflammation in driving the pathogenesis of non-AIDS-defining conditions has been studied and established, although not as clearly in the lung $(6,16,17)$. Although HIV has not been shown to directly infect pulmonary vascular endothelial cells $(18,19)$, there are many possible pathways for HIV infection to cause vascular dysfunction such as those found in the nonsmokers living with HIV in our study. For instance, HIV viral antigens present in the pulmonary endothelium may directly stimulate abnormal growth and proliferation, causing vascular dysfunction $(18,20)$. Additionally, the 
chronic inflammatory state and persistent immune activation and dysregulation in HIV infection could induce the release of proinflammatory cytokines that have been invoked in the development of pulmonary vasculopathies (21). Finally, although it is unknown how HIV infection affects the vasculature of the bronchial circulation, HIV may promote leukocyte emigration via the bronchial circulation (22) or cause bronchial vessel remodeling contributing airway wall changes (23), similar to the effects of smoking-related vascular changes in the development of COPD.

These regional perfusion abnormalities in nonsmoking patients living with HIV are similar to smoking patients, indicating that the vascular dysfunction caused by HIV infection alone may contribute to the development of emphysema in this population. Our data showing nearly all subjects regardless of smoking status with a vertical perfusion gradient attenuated below the range of controls were living with HIV (Fig. 4) is additional evidence that the vascular dysfunction caused by HIV infection may be crucial to the enhanced emphysema susceptibility seen in individuals living with HIV. Further longitudinal study is required to test this hypothesis.

In our study, smokers, regardless of HIV infection, also demonstrated significantly reduced vertical gradients in perfusion and greater residual perfusion heterogeneity compared with controls. Hypoxic pulmonary vasoconstriction is normally blocked by inflammation maintaining perfusion in inflamed areas $(24,25)$. In animals exposed to tobacco smoke, however, pulmonary vascular abnormalities cause ongoing vasoconstriction and precede emphysema development (26-28). Using functional imaging, our group and others demonstrated perfusion heterogeneity in smokers with early emphysema susceptibility $(8,29)$. The inability of smokers to maintain perfusion in inflamed regions due to failure to block hypoxic pulmonary vasoconstriction (ongoing vasoconstriction) may be the critical event in the pathogenesis of emphysema $(7,30)$. Our study supports these prior findings showing increased residual perfusion heterogeneity in smokers.

In smokers living with HIV, the vertical gradient in perfusion was severely reduced, likely due to early but increasing pulmonary vascular pressures counteracting the effects of hydrostatic pressure. Our study did not find a significant difference in regional pulmonary perfusion between smokers living with and without HIV infection. Inflammation and oxidative stress from smoking alone may cause perfusion changes beyond any additive immune dysfunction of HIV infection in the smoking group. However, we also observed a decremental trend toward loss of the vertical gradient in perfusion from nonsmokers living with HIV $(-5.32 \pm$ $\left.1.8310^{-2} \mathrm{~cm}^{-1}\right)$ to smokers without HIV infection $(-4.88 \pm 1.79$ $\left.10^{-2} \mathrm{~cm}^{-1}\right)$ to smokers living with HIV $\left(-4.7 \pm 1.6610^{-2} \mathrm{~cm}^{-1}\right)$.

As half of our cohort underwent echocardiography with normal results, our results reveal that perfusion imaging can detect much earlier stages of pulmonary vascular dysfunction, such as changes in the gradients of perfusion, compared with current conventional noninvasive methods of assessment. Also, our results showing increased residual perfusion heterogeneity and a diminished vertical gradient in perfusion in all nonsmokers living with HIV (Fig. 2) indicate that HIV-associated pulmonary vascular dysfunction may be more common than previously recognized. However, it is not possible to determine with certainty if the perfusion abnormalities we have found are a primary defect or secondary to ventilation abnormalities.

Limitations of the ${ }^{13} \mathrm{NN}$ imaging technique have been discussed in detail $(14,15)$, including the lower resolution of PET scans compared with CT or MRI scans. However, the ${ }^{13} \mathrm{NN}$-bolus method allows functional imaging of both pulmonary perfusion and specific ventilation using a single injection. ${ }^{13} \mathrm{NN}$ tracer kinetics and image misalignments can affect the accuracy of noise-free $\mathrm{CV}^{2}$ parameters. However, such errors occurring randomly should only diminish differences among groups and bias results toward the null hypothesis of statistical tests. Finally, despite notable differences observed with our current sample size, future studies in larger sample sizes followed longitudinally are required.

\section{CONCLUSION}

In subjects with well-controlled HIV and minimal radiographic emphysema, both HIV infection and smoking are associated with an increased fraction of residual perfusion heterogeneity and a reduction in the vertical gradient of perfusion. These findings may precede the development of overt lung disease, which represents an opportunity for earlier risk prediction, preventive strategies, and alternate therapeutic targets.

\section{DISCLOSURE}

This work was supported by grants to Dr. Ben Medoff (NIH 1U01HL121827-01) and Dr. Douglas Kwon (1R01DA042685-01). No other potential conflict of interest relevant to this article was reported.

\section{ACKNOWLEDGMENTS}

We thank the staff from the Massachusetts General Hospital Departments of Nuclear Medicine and Nuclear Pharmacy for their assistance with this project, including Steve Weise, Michael Cournoyer, John Correia, Eugene Lee, Peter Rice, Melissa Bruen, Erin Beloin, Kevin Vernon, and Daniel Yokell. In addition, we extend kind thanks to the staff at the Ragon Institute for their assistance with recruitment and Rebecca Harris for her contributions to mask creation.

\section{KEY POINTS}

QUESTION: Does chronic HIV infection promote pulmonary vascular dysfunction manifesting as increased pulmonary perfusion heterogeneity before tissue destruction (emphysema) in the lung parenchyma?

PERTINENT FINDINGS: In a study of 46 smokers and nonsmokers living with and without HIV who underwent CT and ${ }^{13} \mathrm{~N}\left({ }^{13} \mathrm{NN}\right)$ PET scans, nonsmokers living with HIV had a significantly greater perfusion heterogeneity and reduced vertical gradient of perfusion compared with controls. These perfusion abnormalities were similar to smokers.

IMPLICATIONS FOR PATIENT CARE: These data indicate the onset of subclinical pulmonary perfusion abnormalities that may herald the development of significant lung disease in individuals living with HIV.

\section{REFERENCES}

1. Drummond MB, Kirk GD. HIV-associated obstructive lung diseases: insights and implications for the clinician. Lancet Respir Med. 2014;2:583-592.

2. Morris A, George MP, Crothers K, et al. HIV and chronic obstructive pulmonary disease: is it worse and why? Proc Am Thorac Soc. 2011;8:320-325.

3. Gingo MR, Morris A. Pathogenesis of HIV and the lung. Curr HIV/AIDS Rep. 2013;10:42-50.

4. Raynaud C, Roche N, Chouaid C. Interactions between HIV infection and chronic obstructive pulmonary disease: clinical and epidemiological aspects. Respir Res. $2011 ; 12: 117$ 
5. Marshall MM, McCormack MC, Kirk GD. Effect of cigarette smoking on HIV acquisition, progression, and mortality. AIDS Educ Prev. 2009;21: 28-39.

6. Plaeger SF, Collins BS, Musib R, Deeks SG, Read S, Embry A. Immune activation in the pathogenesis of treated chronic HIV disease: a workshop summary. AIDS Res Hum Retroviruses. 2012;28:469-477.

7. Iyer KS, Newell JD, Jin D, et al. Quantitative dual-energy computed tomography supports a vascular etiology of smoking-induced inflammatory lung disease. Am J Respir Crit Care Med. 2016;193:652-661.

8. Vidal Melo MF, Winkler T, Harris RS, Musch G, Greene RE, Venegas JG. Spatial heterogeneity of lung perfusion assessed with ${ }^{13} \mathrm{~N}$ PET as a vascular biomarker in chronic obstructive pulmonary disease. J Nucl Med. 2010;51:57-65.

9. Bigna JJR, Sime PSD, Koulla-Shiro S. HIV related pulmonary arterial hypertension: epidemiology in Africa, physiopathology, and role of antiretroviral treatment. AIDS Res Ther. 2015;12:36.

10. Harris RS, Winkler T, Tgavalekos N, et al. Regional pulmonary perfusion, inflation, and ventilation defects in bronchoconstricted patients with asthma. Am J Respir Crit Care Med. 2006;174:245-253.

11. Harris RS, Winkler T, Musch G, et al. The prone position results in smaller ventilation defects during bronchoconstriction in asthma. J Appl Physiol. 2009;107: 266-274.

12. Kelly VJ, Hibbert KA, Kohli P, et al. Hypoxic pulmonary vasoconstriction does not explain all regional perfusion redistribution in asthma. Am J Respir Crit Care Med. 2017;196:834-844.

13. Winkler T, Melo MFV, Degani-Costa LH, et al. Estimation of noise-free variance to measure heterogeneity. PLoS One. 2015;10:e0123417.

14. Vidal Melo MF, Layfield D, Harris RS, et al. Quantification of regional ventilation-perfusion ratios with PET. J Nucl Med. 2003;44:1982-1991.

15. Musch G, Layfield JDH, Harris RS, et al. Topographical distribution of pulmonary perfusion and ventilation, assessed by PET in supine and prone humans. J Appl Physiol. 2002;93:1841-1851.

16. Deeks SG, Tracy R, Douek DC. Systemic effects of inflammation on health during chronic HIV infection. Immunity. 2013;39:633-645.

17. Klatt NR, Chomont N, Douek DC, Deeks SG. Immune activation and HIV persistence: implications for curative approaches to HIV infection. Immunol Rev. 2013;254:326-342.
18. Kanmogne GD, Primeaux C, Grammas P. Induction of apoptosis and endothelin1 secretion in primary human lung endothelial cells by HIV-1 gp120 proteins. Biochem Biophys Res Commun. 2005;333:1107-1115.

19. Humbert M, Monti G, Fartoukh M, et al. Platelet-derived growth factor expression in primary pulmonary hypertension: comparison of HIV seropositive and HIV seronegative patients. Eur Respir J. 1998;11:554-559.

20. Mermis J, Gu H, Xue B, et al. Hypoxia-inducible factor-1 $\alpha$ /platelet derived growth factor axis in HIV-associated pulmonary vascular remodeling. Respir Res. 2011;12:103.

21. Morse JH, Barst RJ, Itescu S, et al. Primary pulmonary hypertension in HIV infection: an outcome determined by particular HLA class II alleles. Am J Respir Crit Care Med. 1996;153:1299-1301.

22. Davis BB, Shen Y-H, Tancredi DJ, Flores V, Davis RP, Pinkerton KE. Leukocytes are recruited through the bronchial circulation to the lung in a spontaneously hypertensive rat model of COPD. PLoS One. 2012;7:e33304.

23. Hashimoto M, Tanaka H, Abe S. Quantitative analysis of bronchial wall vascularity in the medium and small airways of patients with asthma and COPD. Chest. 2005;127:965-972.

24. Schuster DP, Marklin GF. The effect of regional lung injury or alveolar hypoxia on pulmonary blood flow and lung water measured by positron emission tomography. Am Rev Respir Dis. 1986;133:1037-1042.

25. Gust R, Kozlowski J, Stephenson AH, Schuster DP. Synergistic hemodynamic effects of low-dose endotoxin and acute lung injury. Am J Respir Crit Care Med. 1998;157:1919-1926.

26. Wright JL, Churg A. Advances in the pathology of COPD. Histopathology. 2006;49: $1-9$.

27. Seimetz M, Parajuli N, Pichl A, et al. Inducible NOS inhibition reverses tobaccosmoke-induced emphysema and pulmonary hypertension in mice. Cell. 2011;147: 293-305.

28. Ferrer E, Peinado VI, Castañeda J, et al. Effects of cigarette smoke and hypoxia on pulmonary circulation in the guinea pig. Eur Respir J. 2011;38:617-627.

29. Alford SK, van Beek EJR, McLennan G, Hoffman EA. Heterogeneity of pulmonary perfusion as a mechanistic image-based phenotype in emphysema susceptible smokers. Proc Natl Acad Sci USA. 2010;107:7485-7490.

30. Hueper K, Vogel-Claussen J, Parikh MA, et al. Pulmonary microvascular blood flow in mild chronic obstructive pulmonary disease and emphysema. The MESA COPD Study. Am J Respir Crit Care Med. 2015;192:570-580. 